\title{
Shedding light on an unknown reality in solid organ transplant patients' self- management: A contextual inquiry study
}

Jasper M.M. Vanhoof, RN, MscN, $\mathrm{PhDc}^{1}$; Bert Vandenberghe, MscEng'2; David Geerts, $\mathrm{PhD}^{2}$; Pieter Philippaerts, MscTech, $\mathrm{PhD}^{3}$; Patrick De Mazière, MscEng, PhD³ ; Annette DeVito Dabbs, RN, PhD, ACNSBC, FAAN 4; Sabina De Geest, RN, PhD, FAAN, FRCN, FEANS ${ }^{1,5}$; Fabienne Dobbels, PhD ${ }^{1,5}$; on behalf of the PICASSO-Tx consortium

Author information: ${ }^{1}$ Academic Centre for Nursing and Midwifery, Department of Public Health and Primary Care, KU Leuven, Leuven, Belgium; ${ }^{2}$ Meaningful Interactions Lab (Mintlab), imec, KU Leuven, Leuven, Belgium; ${ }^{3}$ ITech, UC Leuven-Limburg, Leuven, Belgium; ${ }^{4}$ School of Nursing, Department of Acute and Tertiary Care, University of Pittsburgh, Pittsburgh, USA; ${ }^{5}$ Institute of Nursing Science, Department Public Health, University of Basel, Basel, Switzerland

Collaborators of the PICASSO-Tx consortium: Lieven Dupont, MD, PhD; Dirk Kuypers, MD, PhD; Diethard Monbaliu, MD, PhD; Frederik Nevens, MD, PhD; Jacques Pirenne, MD, PhD; Thierry Troosters, PhD; Johan Van Cleemput, MD, PhD; Johan Vanhaecke, MD, PhD; Dirk Van Raemdonck, MD, PhD; Geert Verleden, $\mathrm{MD}, \mathrm{PhD}$; Robin Vos, MD, PhD

Running head: Contextual inquiry in transplantation

Address for correspondence: Fabienne Dobbels, KU Leuven, Department of Public Health and Primary Care, Academic Centre for Nursing and Midwifery, Kapucijnenvoer 35/4, 3000 Leuven, Belgium Tel: +32 16 37.34.02; Fax: +32 16 33.69.70; E-mail: fabienne.dobbels@kuleuven.be

E-mail addresses of all co-authors: jasper.vanhoof@kuleuven.be; bert.vandenberghe@kuleuven.be; david.geerts@kuleuven.be; pieter.philippaerts@ucll.be; patrick.demaziere@ucll.be; ajdst42@pitt.edu; sabina.degeest@unibas.ch

Conflicts of interest: None

Acknowledgements: The authors would like to thank all participants for welcoming us in their homes, as well as Hélène Schoemans (MD) to perform the backwards translation of the interview quotes.

Funding: This project was funded by a research grant from the Research Council of KU Leuven (OT13-101)

\section{Author contributions}

- Jasper M.M. Vanhoof: Conceptualization of the study, data collection, data analysis, drafting the manuscript and collaborator in the final approval of the version to be published;

- Bert Vandenberghe: Conceptualization of the study, data collection, data analysis, critical revising of the manuscript drafts and collaborator in the final approval of the version to be published

- David Geerts: Conceptualization of the study, feedback on how to perform data analysis, critical revising of the manuscript drafts and collaborator in the final approval of the version to be published

- Pieter Philippaerts, Patrick De Mazière, Annette DeVito Dabbs, Sabina De Geest: Conceptualization of the study, critical revising of the manuscript drafts and collaborator in the final approval of the version to be published

- $\quad$ Fabienne Dobbels: Conceptualization of the study, data analysis, critical revising of the manuscript drafts and collaborator in the final approval of the version to be published 


\section{Abstract page}

Authors surnames and initials: Vanhoof, J.M.M.; Vandenberghe, B.; Geerts, D.; Philippaerts, P.; De Mazière, P.; DeVito Dabbs, A.; De Geest, S.; Dobbels, F.; on behalf of the PICASSO-Tx consortium

Manuscript title: Shedding light on an unknown reality in solid organ transplant patients' self-management: a contextual inquiry study

Journal title: Clin Transplant.

Key words: transplantation; contextual inquiry; adherence; medication; lifestyle; needs; self-management Name and address corresponding author: Fabienne Dobbels, KU Leuven, Department of Public Health and Primary Care, Academic Centre for Nursing and Midwifery, Kapucijnenvoer 35/4, 3000 Leuven, Belgium

Abstract: Traditional quantitative and qualitative research methods inadequately capture the complexity of patients' daily self-management. Contextual inquiry methodology, using home visits, allows a more indepth understanding of how patients integrate immunosuppressive medication intake, physical activity and healthy eating in their daily lives, and which difficulties they experience when doing so. This mixed-method study comprised two home visits in 19 purposively selected adult heart, lung, liver and kidney transplant patients, asking them to demonstrate how they implement the aforementioned health behaviours. Meanwhile, conversations were audiotaped and photos taken. Audio-visual materials were coded using directed content analysis. Difficulties and supportive strategies were identified via inductive thematic analysis. We learned that few patients understood what 'sufficiently active' means. Physical discomforts and poor motivation created variation across activity levels observed. Health benefits of dietary guidelines were insufficiently understood, and their implementation into everyday life considered difficult. Many underestimated the strictness of immunosuppressive medication intake, and instructions on handling late doses were unclear. Interruptions in routine and busyness contributed to non-adherence. We also learned that professionals often recommend supportive strategies, which patients not always like or need. This contextual inquiry study revealed unique insights, providing a basis for patient-tailored self-management interventions. 


\section{Introduction}

The therapeutic regimen after solid organ transplantation $(\mathrm{Tx})$ is complex, consisting of adherence to the immunosuppressive medication, limited or no alcohol use, abstinence from smoking, sufficient physical activity and healthy eating habits, among other health behaviours. Many transplant patients struggle with integrating this complex regimen into their daily lives, with the highest non-adherence rates being reported for physical activity, medication intake and following a diet, occurring in 19 to 25 cases per 100 patients per year, respectively (1). This increases the risk for rejection, cardiovascular and metabolic comorbidities (e.g. hypertension and diabetes), and ultimately mortality (2-4). Yet, before effective interventions can be developed, a better understanding of why transplant patients find it difficult to follow these health behaviours is needed. Unfortunately, unlike risk factors for medication non-adherence, risk factors for insufficient physical activity or poor diet received far less attention thus far (5-10). Furthermore, existing studies mostly used quantitative designs, presenting patients with questionnaires consisting of a predetermined list of possible non-adherence reasons or lifestyle problems $(5,6,11-13)$. This approach rarely allows participants to add other difficulties they experience, nor share strategies they might use to manage these risk factors. Qualitative studies using focus groups or semi-structured interviews can provide a more in-depth understanding of difficulties experienced $(7-9,14,15)$. Yet, such studies do not provide insight on how these health behaviours are actually performed by patients on a day-to-day basis, which in part might explain why many adherence interventions tested thus far were not effective $(16,17)$. Adopting a contextual inquiry methodology might help overcome many shortcomings of these more "traditional" research methods (18).

Indeed, contextual inquiry involves observing and interacting with participants in their daily context (i.e. at their homes), where they actually perform the behaviours of interest (18). This allows researchers to obtain an accurate snapshot of the context of patients' medication taking, physical activity and eating habits, including the difficulties encountered and potential strategies used to overcome some of these difficulties. By considering patients as "real-life experts", and using a combination of methods to learn from them (e.g. observation, taking photos, conversations), researchers can gain a deeper and shared understanding of 
patients' needs for supportive interventions. To our knowledge, only one study used contextual inquiry methodology in transplant patients, investigating how lung transplant patients perform self-monitoring of e.g. spirometry and blood pressure (19). Therefore, using contextual inquiry methodology, the aims of this study were to inform the design of future interventions by: 1) understanding how transplant patients currently perform and organize their physical activity, eating habits and immunosuppressive medication adherence in their daily lives, and 2) identifying the problems they experience in doing so.

\section{Methodology}

The 'Consolidated criteria for reporting qualitative studies (COREQ)'-checklist guided the manuscript (20).

\section{Design and sample}

This mixed-method, contextual inquiry study used purposive sampling to select 20 Dutch-speaking adult ( $\geq$ 18 years) heart, lung, liver and kidney transplant patients from the University Hospitals of Leuven (5 patients per transplant group) from a list of 122 transplant patients, who participated in a previous study on use of Information and Communication Technologies (ICT) (21). Invited participants ranged in sex, age, educational level, employment, marital status, type and time post-Tx and experience with ICT (i.e. actual use of ICT), as these characteristics could impact patients' adherence.

\section{Data collection}

Following the methodology of Holtzblatt and Beyer (18), we conducted two home visits per participant between December 2013 and February 2014.

\section{Assessment of transplant participants' weekly schedule}

During the first home visit, we provided participants with a diary that was based on the behavioural model of persuasive design $(22,23)$. This allowed them to note daily activities and map their medication taking, physical activity and eating habits, as well as accompanying feelings, perceptions and circumstances. The 
diary included written instructions and examples of activities that could be recorded. Participants were instructed to record physical activity and eating habits immediately after performing the behaviours, while medication taking only needed to be recorded when they forgot or were late in taking immunosuppressive medications (see online supplementary files for an example of the diary and the physical activity sheet, respectively).

\section{Contextual inquiry interview}

Two researchers (J.M.M.V, Masters' prepared nurse, and B.V., Masters' prepared engineer and humancentred design expert with contextual inquiry expertise; not involved in transplant care) conducted all second home visits together, lasting about two hours each. Following the principles of contextual inquiry interviewing, participants were considered experts in performing their self-management behaviours, and were told that the researchers were there to learn from them (18). Participants were invited to share details of their experiences and perceptions, and encouraged to show and explain how, when, where, why and with whom they performed the respective health behaviours. Examples of questions asked can be found in interview quotes that are placed throughout the findings-section. The diary served as guide to facilitate the conversation and observations, yet, the interview was not limited to what participants had written down in the previous week. These 'real-life' demonstrations allowed observing participants' normal routines, including strategies/solutions they used and hindrances they encountered. By combining the interview, field notes and photos of these real-life experiences, and regularly checking with the participants in a nonjudgemental way whether our interpretations were correct, we created a deep and shared understanding of participants' daily medication adherence, physical activity and eating habits. Figure $1 \mathbf{A}$ and $\mathbf{B}$ show typical contextual inquiry interview scenes.

\section{Procedure}

The study was approved by the hospital's Ethical Committee and conducted in concordance with prevailing guidelines $(24,25)$. Eligible patients were called and invited to participate. If interested, participants provided their home address, and a convenient date for the first home visit was arranged. During this visit, 
the researchers explained the study, and participants signed the informed consent form, ensuring absolute confidentiality of the recorded interviews and photos taken. Next, they were asked to complete the diary, and a second home visit was scheduled within a week. Patients received a €30 coupon for their participation.

\section{Analysis}

The interviews were verbatim transcribed and merged with participants' characteristics, photos and field notes in participant-specific folders. The same researchers who performed the home visits, as well as the principal investigator (F.D.; self-management expert), independently and repeatedly read the interviews, captured and coded relevant quotes using directed content analysis, and marked visual materials to answer the research question (26). Subsequently, all identified codes were compared during a meeting, supported by the participant folders. Inductive thematic analysis were used to group codes referring to similar themes, representing meaningful categories of factors hindering or helping medication adherence, physical activity or eating habits. This coding scheme was iteratively discussed until no further changes were needed. In a last step, the final coding scheme was applied to the 19 interviews, linking relevant quotes to the agreedupon themes. Descriptive statistics were used to summarize the hindrances and enablers for each health behaviour into grids, which were also used to identify potential avenues for supportive interventions. The analysis was conducted in Dutch. For the purpose of this manuscript, we carefully selected quotes that accurately expressed our different findings and observations, which were subsequently translated in English by one researcher (J.M.M.V.), and checked by the other two researchers who collaborated in the data analysis. Additionally, one researcher (native English speaker, fluent in Dutch language and not involved in this study) performed a backwards translation from the English quotes to Dutch to verify comparability of wording and meaning of the translated and original quotes. 


\section{Findings}

\section{Participant sample and general contextual observations}

Twenty patients were selected, of which three refused because of no interest $(n=1)$ or practical reasons $(n=2)$. Three new participants with similar characteristics replaced these patients. One participant droppedout because of a medical emergency, resulting in a sample of 19 transplant participants from all over Flanders and the Netherlands $(n=1)$ (Table 1 provides their characteristics).

Most participants welcomed us warmly. Six had a family member or friend present. We witnessed considerable differences in participants' general living conditions, as illustrated by two observation excerpts: 'Participant 12 and her husband live in a small, but modern apartment. We immediately notice how clean and well organized everything is ... She explains that her whole life is dominated by her Tx and avoiding infections. Therefore, she cleans every day and even pours chlorine in the dishwasher'; 'Participant 13 leads us upstairs where a damp and cigarette smell is present. When entering her living room, full ashtrays and cigarettes lie on the table and the linoleum floor is dirty and curling upwards. A friend sits in a chair and lights up a cigarette.' Our main findings in view of physical activity, eating habits and medication taking are summarized below.

\section{Physical activity}

Most participants deemed physical activity important to remain healthy and prevent physical deterioration $(n=10)$, such as muscle stiffness, dialysis, and especially weight gain:

'I need to remain active, otherwise my weight will increase' (Participant 15).

Yet, many participants were not able to describe what sufficient activity entails. Most physical activity was obtained from executing activities of daily living, such as cleaning, shopping and working, and participants considered these activity levels as being sufficient: 
'Why would I exercise? Where would I go? I'm not going anywhere without a goal, I do everything on foot' (Participant 10).

However, as Table 2A shows, participants experience a range of factors that limit them in their physical activity. Bad weather is the most prominent $(n=12)$, with nearly all stating to be more active during summer. Eight participants acknowledged being too tired or lacking sufficient energy regularly, with explanations ranging from their age ('I'm 66, not a young person anymore' (Participant 9)), to being too tired from their daily activities ('I did my groceries and then visited a friend in the hospital, I was so tired' (Participant 13)). In between was 'physical discomforts' ( $n=11)$, with mainly pain, muscle cramps and shortness of breath:

'When I was ready assembling that IKEA-closet, it felt like I ran a marathon, I completely collapsed and took the next day off' (Participant 5).

These factors caused some participants to stay at a limited activity level, while others tried certain strategies to increase their activity.

More specifically, being active with others (e.g. participating in a walk that was organized by the patient association), was an enjoyable strategy for six participants. Furthermore, this created opportunities for social control, since occasionally not participating in these organized activities most often resulted in receiving a phone call from their peers asking why they did not participate. Others added extra activity to their daily chores, e.g. by walking to work instead of taking the car. In addition, eight participants stated that they owned a stationary bicycle or cross step:

'That will be here!' [Participant 15 points at the living room where seats are put aside and a stationary bicycle is facing the television] 'I have balancing problems, so this is ideal. I ride it every day while watching the news, sometimes even with my pyjamas on.'

However, we witnessed that possessing fitness equipment did not equal using it, as illustrated by the partner of participant 9: 
'He should ride it for his legs, but it's too cold in the porch....'

When probing participants further, we learned that finding solutions to overcome these difficulties would presumably not help, as insufficient motivation was often the underlying reason:

'...I shouldn't look for excuses, if it would stand here, I still wouldn't use it, I don't really like being active.' (Participant 9)

'Yes, I rode it [stationary bicycle] on Sunday. (Researcher) And where does it stand, can we have a look? [Participant 3 takes us to his bedroom where the outside wind blows underneath the door, making it very cold. We observe how he moves a large cupboard and drags a very old stationary bicycle with rusted pedals to the centre of the room.] I don't really like it, and I'm often too busy as well.'

\section{Eating habits}

Table 2B summarizes the main findings in view of healthy eating. The majority of participants declared having sufficient knowledge and could explain, albeit not always in great detail, what healthy eating entails. Only participant 11 claimed not having a diet.

However, not all participants understood why following a diet was good for their health:

'Because if you're transplanted, are your blood vessels more sensitive to fat? They tell us to take care of our foods, but sometimes you wonder why' (Participant 19).

In addition, knowing how to translate all 'hospital dietary and eating instructions' into daily life was by far the most frequent difficulty participants encountered:

'Actually, I know very well what I'm expected to do. Doing it, that's something else' (Participant 4). 
Six participants stated that their diet was difficult to follow, because they experienced issues in getting used to low sodium foods or missed eating raw foods. Likewise, six participants admitted to violate the guidelines occasionally:

'(Partner of participant 3) I like eating my steak medium rare. It should be well done for him, but we don't like that. (Participant) I just take a very small piece then.'

Being tired of eating the same foods was also perceived as difficult:

'Actually, I should eat more vegetables, but sometimes I'm just fed up with it. [sighs] Always lettuce and carrots, I'm not a rabbit you know!' (Participant 13).

Finally, the majority of participants $(n=11)$ indicated that healthy eating was time consuming, as witnessed by the commonly heard phrase:

'I didn't have time to cook, so I drove to the take-away' (Participant 14).

Some participants were very creative in finding ways to overcome hindrances:

'(Participant 6) I keep a lot of things in an Excel-file on my computer. (Researcher) That sounds interesting! Is it possible to show us? (Participant) Sure, but we'll have to go upstairs... [Participant leads us upstairs] I always ask a printout of my blood results in the hospital and when I'm home, I enter them here and it shows in this graph. Here you see my personal creatinine level and the ideal and permitted level (see Figure 2A). It's still too high, but I'm making progress. Same here for my weight: I stand on the scale every day, enter it and I see it in the graph (see Figure 2B). The doctor told me that $80 \mathrm{~kg}$ is my ideal weight. I'm not there yet, but I'm under my own target weight! [Researcher] And do these graphs motivate you to make any changes? (Participant) Yes, if something is rising, I watch what I eat. I'm so afraid of becoming a diabetic!' 
'You're going to laugh, but I really like candy, so we try to keep it out of the house. But sometimes, my wife buys some and if I want one, I have to ask her. I get a maximum of four per evening, she's very strict [laughs]' (Participant 9).

Yet, many participants only succeeded partly, for instance by choosing healthier alternatives $(n=9)$, but they mostly did so for a single product and not for all food purchased (e.g. light vs. dairy butter). Furthermore, some choices were mistakenly held for healthier:

'I have to avoid salt. I do use sea salt sometimes and that's not a problem ...' (Participant 19).

Additionally, deviations from personal routines, like having visitors $(n=4)$ or holidays $(n=3)$, or unexpected events, tended to make 'guideline adherence' more difficult:

'On Sunday morning, my children and grandchildren came over. Then we have a full breakfast: I go to the bakery, bake eggs and bacon, and everything that goes with it' (Participant 14).

'It was half past seven and she (partner) wasn't home yet, so I took a snack before dinner' (Participant 5).

\section{Immunosuppressive medication adherence}

The vast majority of participants understood the importance of taking their immunosuppressive medication, as well as taking them every day at the same time (i.e. importance of regularity of medication intake), and many found ways to make medication taking a routine.

'It is too important if I think about the donor, his family and the people from Leuven [hospital] who did a fantastic job' (Participant 7).

At first it was 8AM and 8PM, but I gradually changed it to 12 o'clock. I'm a student and I found out those are better hours. If I want to go out, I don't want to wake up the next morning at 8AM to take my medication' (Participant 17). 
However, as Table $\mathbf{2 C}$ shows, participants found it unclear how strictly the medication regimen needs to be followed and what an 'acceptable deviation of the usual hour of intake' is, with quotes ranging from 'They say it's okay to take your medication up to 4 hours after your scheduled time of intake' (Participant 1) to '8 o'clock is 8 o'clock. It's never 7 h30 or 7h45, always 8, every day!' (Participant 12). These broad interpretations often were consequences of believing that immunosuppressive medication do not always need to be taken at the same time that strictly, and the transplant team often played a role in this misconception $(n=6)$ :

I've never had problems with rejection before. It's no use to get up in the morning, take your pills, don't eat anything and go back to bed, so I just take them when I wake up. Sleep is important too!' (Participant 9)

'I can't take my pills when going to the outpatient clinic. I have to take them when I leave and it's sometimes noon, so it's probably not that important' (Participant 11).

Many patients also did not know what to do when being late with their medication, and do what seems to be most logic to them:

'If I'm 3 hours late, I still take them, if I find out in the middle of the night, I wait for the next dose.' (Participant 16);

'If there's like a 2 hour difference, and it's 12PM, I take them, but I wait with my next dose until 11, and take my evening dose at 10PM again' (Participant 5).

We also witnessed how participants used a wide array of strategies to facilitate medication taking. More specifically, participants told us how others remind them to take the medication $(n=8)$, like family or even pupils, by placing them in sight $(n=7)$, setting alarms $(n=10)$ and linking medication intakes to other routines $(n=13):$

'I always watch the news at 7PM, and then I know I have to take them' (Participant 3). 
All except two participants took their medication with them when going away:

'That's a method I developed! All the medication I need is in that 'purse' [laughs]. It used to be in a drawer, but that's easy to forget if you're going out. Or I put that one in my pocket if I go to the hospital for example' (Participant 5; see Figure 3).

Moreover, six participants kept spare medication at various places, like in the car, in case they forgot their medication at home. Most participants also have a routine in preparing medication, by keeping a small medication stock in a closet, drawer or box, or by having a fixed time $(n=11)$ or place $(n=7)$ to prepare them in smaller cups for the upcoming days or the next scheduled intake. Furthermore, some keep track of their stock and intakes in a diary or Excel-file:

'(Researcher) Do you prepare your medication in advance? (Participant 3) Yes, I take my pills at 7.30 $A M$, go for a little rest, and then I prepare my medication here [living room] for the evening and the next morning. (Researcher) So that's something you do every day? (Participant) Every day! It's a routine. I take the pills out of this big box I bought 7 years ago, and take them out of the package, because I recognize them without it. Next, I put them in these plastic cups with the hours written on, can't miss! My wife always does a double check. Then I place them on the box with my thermometer, the thing to blow on [spirometer] and my diary and put them by the sink (See Figure 4A). (Researcher) You mention the diary, could you explain that? (Participant) Yes [opens diary], here I write my daily temperature, the number I've blown and the weekly weight. And here, I fill in my medication: red for the morning, blue for the evening' (See Figure 4B).

Yet, these strategies were not "panaceas", as many still experienced adherence issues, because of falling asleep or oversleeping $(n=3)$, forgetfulness $(n=5)$, being busy $(n=11)$ or interruptions in their routines $(n=14)$ :

'We had a Christmas party and my family came over. It [cell phone] was lying next to me, it went off and I thought 'I'll do it later' because we were talking. So I told my partner to bring them 
[medication] to me, but he was busy in the kitchen. I saw them standing when we were cleaning up, I felt so bad! (Participant 1)

Some were aware of available solutions, but considered these not suitable for them for various reasons:

'(Participant 14) I sometimes fall asleep in the evening in front of the television, when my husband is not at home. (Researcher) And have you ever thought about tools or methods that might help you? (Participant) I know many people who set the alarms of their cell phone, but that wouldn't work for me. It already contains so many alarms from my agenda, it wouldn't work'.

In contrast, some participants did use strategies, often presented by transplant professionals, which they found unhelpful, cumbersome or even hated:

(About the diary offered to monitor medication intake and vital signs) 'When we're in the waiting room at the outpatient clinic, we very often see other patients quickly filling in their medication intakes and temperatures in their diary, unbelievable! [...] I do always mark most of my medication intakes for the upcoming weeks, because I don't like filling it in (see Figure 4B). If something does change along the way, I just delete it. Now it's already filled in until February. (Researcher) And do you do this for yourself? (Participant) For the hospital, the outpatient clinic, so they can see how I'm doing'

'I hate that medication box! (see Figure 5) I don't want to use it. It's not easy to use. (Partner of Participant 9) He has to drag it with him on the train together with his other things if he needs to go to the hospital. (Researcher) So you do take the box with you? (Participant) We have to! But I never put my pills in it, we have our own system. So I only fill it when I need to go to the hospital'.

\section{Discussion}

Except for one study in lung transplantation that focused on monitoring vital signs (19), to our knowledge, this is the first study that applied a contextual inquiry methodology in solid organ transplantation. In the 
next paragraphs, we discuss our novel insights on how people implement physical activity, eating habits and immunosuppressive medication adherence in daily life, the problems they encounter, the strategies they already have in place, and opportunities for tailored interventions.

Our finding that many transplant patients had insufficient knowledge on what sufficient physical activity entails is consistent with other studies $(12,27)$, and partly explains the large variability in physical activity levels observed. However, educating patients on the state-of-the-art guidelines of '150 minutes of moderate activity per week' or ' 10.000 steps per day' $(28,29)$ will unlikely be sufficient, as physical discomfort (e.g. pain, tiredness) also prevent transplant patients from being active $(11,12,15,27)$. Hence, the specific causes for these symptoms should be clarified for each patient, and result in tailored alleviation strategies if possible (e.g. by prescribing supervised exercise programs or pain medication). Moreover, because of the large variability in activity levels, physical activity goals should be individualized and gradually increased $(30,31)$. Additionally, we learned that lack of motivation often underpins suboptimal activity levels. Given that theoretical models indicate that intention is the most important driver of behaviour, strategies that can boost ones' physical activity, such as motivational interviewing, are recommended (32).

With regard to eating habits, Gordon and colleagues likewise found that transplant patients not always understand why dietary guidelines are important for their health (27). Although a refreshment course on the benefits of healthy eating could be helpful, educating patients again on the reasoning behind dietary guidelines is not desirable, given that they already understand what healthy eating entails. Similar to findings reported by other transplant or general population studies, our patients rather struggle to implement these guidelines in their everyday lives for various reasons, such as lack of time and lack of inspiration for variation $(5,27,33)$. Examples of weekly meal plans with tasteful foods that are easy and quick to prepare, as well as menus for special occasions could potentially help to sustain their diet.

Regarding medication adherence, we found that most participants understand that their immunosuppressive medication always needs to be taken, but some underestimate the importance of 
taking their medication on time. Inaccurate health beliefs, alongside a knowledge deficit on what to do when being late seem to trigger this underestimation. Examples included finding sleep more important than getting up to take the medication, the conviction that it is less important given they have not yet encountered a rejection, or transplant teams being less strict with respect to timing during hospitalisations or outpatient clinic visits. Not understanding why, how and when the medication needs to be taken has previously been described in kidney $T x(6)$. Hence, alongside informing patients about the importance of strictly following the timings of intake, additional interventions should focus on finding a time of intake that fits with each patient's lifestyle, and training them on what to do when being late. On the other hand, it is encouraging to observe that many already have supporting strategies in place, including having a routine in preparing and taking medication, others reminding them to take their medication, and setting alarms ( 7 , 9). Interestingly, participants admitting to forget to take their medication occasionally indicated being aware of alarms, yet did not find these helpful. It would hence be pointless to equip patients with reminders or alarms (34). Moreover, we observed how participants often were obliged to use tools presented by transplant professionals, which were sometimes unhelpful or cumbersome. Based on these novel insights, transplant teams should reconsider these "one-size-fits-all" solutions, and realize that a tailored approach, considering patient's preferences, is more in line with state-of-the-art recommendations on selfmanagement support $(35,36)$.

Supportive interventions can be offered 'face-to-face' during scheduled clinic visits, yet the role of eHealth deserves to be explored further (37). More specifically, interactive health technology allows patients to access or transmit information and receive guidance and support in their daily lives, tailored to their health needs (38). Preliminary evidence in Tx and other chronically ill patients showed that this could be an effective pathway for adherence and lifestyle support, yet further investigation is indicated (39-43).

Our study is not without limitations. Our sample size of 19 participants is small, yet, qualitative studies typically do not need large sample sizes to gain an in-depth understanding of a phenomenon. Furthermore, no new information was detected after 5, 14 and 15 participants for physical activity, eating habits and 
medication adherence, respectively (see online supplementary tables for detailed information to support this conclusion). Some may also question our sample representativeness. However, our participants were chosen from a convenience sample of 122 transplant patients enrolled in a previous study, of which the demographics closely resembled those of solid organ Tx registry reports (21). Hence, we carefully selected a sample of transplant patients with characteristics that reflect this broad range of demographic and clinical characteristics of transplant populations in general, as well as factors that could potentially influence selfmanagement, such as marital status and time since transplant. Table 1 indicates that the demographics of our sample again closely resemble those of the registry reports, as well as the general demographics from our hospital $(44,45)$. Finally, since participants were recruited from a previous study, this could have primed them to respond in a socially desirable way. Yet, we have several reasons to believe that social desirability bias was not present. The focus of the previous study was on patients' ICT use and their preliminary technology preferences, and no questions on adherence or lifestyle problems were asked. Furthermore, participants in the present study were clearly informed that no information would be shared with the Tx program, and the researchers were not affiliated to the Tx team. Lastly, participants were always invited to further illustrate their statements in a non-judgemental way, which helped picturing what is truly happening in their homes.

In conclusion, contextual inquiry uncovered several daily challenges patients face in view of medication taking, physical activity and healthy eating. Interviewing patients in their natural setting proved to be a unique way to identify specific needs for support. Our rich findings will inform the development of tailored 'face-to-face' or innovative interactive health technology-based adherence interventions for adult transplant patients. Other researchers are encouraged to use this methodology when aiming to understand the context in which behaviours take place. 


\section{References}

1. Dew MA, DiMartini AF, De Vito Dabbs A, Myaskovsky L, Steel J, Unruh M, et al. Rates and risk factors for nonadherence to the medical regimen after adult solid organ transplantation. Transplantation. 2007;83(7):858-73.

2. Prendergast MB, Gaston RS. Optimizing Medication Adherence: An Ongoing Opportunity To Improve Outcomes After Kidney Transplantation. Clinical Journal of the American Society of Nephrology : CJASN. 2010;5(7):1305-11.

3. Zelle DM, Corpeleijn E, Stolk RP, de Greef MH, Gans RO, van der Heide JJ, et al. Low physical activity and risk of cardiovascular and all-cause mortality in renal transplant recipients. Clin J Am Soc Nephrol. 2011;6(4):898-905.

4. Zeltzer SM, Taylor DO, Tang WH. Long-term dietary habits and interventions in solid-organ transplantation. J Heart Lung Transplant. 2015;34(11):1357-65.

5. Brocks Y, Zittermann A, Grisse D, Schmid-Ott G, Stock-Giessendanner S, Schulz U, et al. Adherence of Heart Transplant Recipients to Prescribed Medication and Recommended Lifestyle Habits. Prog Transplant. 2017;27(2):160-6.

6. Constantiner M, Cukor D. Barriers to immunosuppressive medication adherence in high-risk adult renal transplant recipients. Dialysis \& Transplantation. 2011;40(2):60-6.

7. Muduma G, Shupo FC, Dam S, Hawken NA, Aballea S, Odeyemi I, et al. Patient survey to identify reasons for non-adherence and elicitation of quality of life concepts associated with immunosuppressant therapy in kidney transplant recipients. Patient preference and adherence. 2016;10:27-36.

8. Israni A, Dean C, Kasel B, Berndt L, Wildebush W, Wang CJ. Why do Patients Forget to Take Immunosuppression Medications and Miss Appointments: Can a Mobile Phone App Help? JMIR public health and surveillance. 2016;2(1):e15.

9. Gordon EJ, Gallant M, Sehgal AR, Conti D, Siminoff LA. Medication-taking among adult renal transplant recipients: barriers and strategies. Transpl Int. 2009;22(5):534-45.

10. Weng FL, Chandwani S, Kurtyka KM, Zacker C, Chisholm-Burns MA, Demissie K. Prevalence and correlates of medication non-adherence among kidney transplant recipients more than 6 months posttransplant: a cross-sectional study. BMC nephrology. 2013;14:261.

11. Sanchez ZV, Cashion AK, Cowan PA, Jacob SR, Wicks MN, Velasquez-Mieyer P. Perceived barriers and facilitators to physical activity in kidney transplant recipients. Prog Transplant. 2007;17(4):324-31.

12. Gustaw T, Schoo E, Barbalinardo C, Rodrigues N, Zameni Y, Motta VN, et al. Physical activity in solid organ transplant recipients: Participation, predictors, barriers, and facilitators. Clin Transplant. 2017;31(4).

13. Zelle DM, Corpeleijn E, Klaassen G, Schutte E, Navis G, Bakker SJ. Fear of Movement and Low SelfEfficacy Are Important Barriers in Physical Activity after Renal Transplantation. PLoS One. 2016;11(2):e0147609.

14. Gordon EJ, Prohaska TR, Gallant MP, Sehgal AR, Strogatz D, Yucel R, et al. Longitudinal analysis of physical activity, fluid intake, and graft function among kidney transplant recipients. Transpl Int. 2009;22(10):990-8.

15. van Adrichem EJ, van de Zande SC, Dekker R, Verschuuren EA, Dijkstra PU, van der Schans CP. Perceived Barriers to and Facilitators of Physical Activity in Recipients of Solid Organ Transplantation, a Qualitative Study. PLoS One. 2016;11(9):e0162725.

16. De Bleser L, Matteson M, Dobbels F, Russell C, De Geest S. Interventions to improve medicationadherence after transplantation: a systematic review. Transpl Int. 2009;22(8):780-97.

17. Marcelino CA, Diaz LJ, Da Cruz DM. The effectiveness of interventions in managing treatment adherence in adult heart transplant patients: a systematic review. JBI database of systematic reviews and implementation reports. 2015;13(9):279-308.

18. Holtzblatt K, Beyer H. Contextual Design Evolved. Carroll JM, editor: Morgan \& Claypool; 2014. 79 p. 
19. De Vito Dabbs A, Myers BA, Mc Curry KR, Dunbar-Jacob J, Hawkins RP, Begey A, et al. Usercentered design and interactive health technologies for patients. Comput Inform Nurs. 2009;27(3):175-83. 20. Tong A, Sainsbury P, Craig J. Consolidated criteria for reporting qualitative research (COREQ): a 32item checklist for interviews and focus groups. International Journal for Quality in Health Care. 2007;19(6):349-57.

21. Vanhoof JMM, Vandenberghe B, Geerts D, Philippaerts P, De Mazière P, DeVito Dabbs A, et al. Technology experience of solid organ transplant patients and their overall willingness to use interactive health technology. Journal of Nursing Scholarship. 2017; In press.

22. Fogg B. A behavior model for persuasive design. Proceedings of the 4th International Conference on Persuasive Technology; Claremont, California, USA. 1541999: ACM; 2009. p. 1-7.

23. Fogg B. Creating persuasive technologies: an eight-step design process. Proceedings of the 4th International Conference on Persuasive Technology; Claremont, California, USA. 1542005: ACM; 2009. p. 1-6.

24. World Medical Association. World Medical Association Declaration of Helsinki: ethical principles for medical research involving human subjects. JAMA. 2013;310(20):2191-4.

25. ICH. ICH Harmonised Tripartite Guideline: Guideline for Good Clinical Practice 1996 [Available from:

http://www.ich.org/fileadmin/Public_Web_Site/ICH_Products/Guidelines/Efficacy/E6/E6_R1_Guideline.p df.

26. Hsieh HF, Shannon SE. Three approaches to qualitative content analysis. Qualitative health research. 2005;15(9):1277-88.

27. Gordon EJ, Prohaska TR, Gallant M, Siminoff LA. Self-care strategies and barriers among kidney transplant recipients: a qualitative study. Chronic Illn. 2009;5(2):75-91.

28. World Health Organization. Global recommendations on physical activity for health Switzerland2010 [Available from: http://apps.who.int/iris/bitstream/10665/44399/1/9789241599979_eng.pdf.

29. Tudor-Locke C, Craig CL, Brown WJ, Clemes SA, De Cocker K, Giles-Corti B, et al. How many steps/day are enough? For adults. The international journal of behavioral nutrition and physical activity. 2011;8:79.

30. Conn VS, Hafdahl AR, Mehr DR. Interventions to increase physical activity among healthy adults: meta-analysis of outcomes. American journal of public health. 2011;101(4):751-8.

31. Michie S, Abraham C, Whittington C, McAteer J, Gupta S. Effective techniques in healthy eating and physical activity interventions: a meta-regression. Health psychology : official journal of the Division of Health Psychology, American Psychological Association. 2009;28(6):690-701.

32. Rubak S, Sandbaek A, Lauritzen T, Christensen B. Motivational interviewing: a systematic review and meta-analysis. The British journal of general practice : the journal of the Royal College of General Practitioners. 2005;55(513):305-12.

33. Smitasiri S, Uauy R. Beyond recommendations: implementing food-based dietary guidelines for healthier populations. Food and nutrition bulletin. 2007;28(1 Suppl International):S141-51.

34. Janamian T, Crossland L, Wells L. On the road to value co-creation in health care: the role of consumers in defining the destination, planning the journey and sharing the drive. The Medical journal of Australia. 2016;204(7 Suppl):S12-4.

35. Nieuwlaat R, Wilczynski N, Navarro T, Hobson N, Jeffery R, Keepanasseril A, et al. Interventions for enhancing medication adherence. Cochrane Database Syst Rev. 2014(11):Cd000011.

36. Rimer BK, Kreuter MW. Advancing Tailored Health Communication: A Persuasion and Message Effects Perspective. Journal of Communication. 2006;56:S184-S201.

37. World Health Organization. eHealth at WHO 2017 [Available from: http://www.who.int/ehealth/en/.

38. Robinson TN, Patrick K, Eng TR, Gustafson D. An evidence-based approach to interactive health communication: a challenge to medicine in the information age. Science Panel on Interactive

Communication and Health. JAMA. 1998;280(14):1264-9. 
39. Murray E, Burns J, See TS, Lai R, Nazareth I. Interactive Health Communication Applications for people with chronic disease. Cochrane Database Syst Rev. 2005(4):CD004274.

40. Thakkar J, Kurup R, Laba TL, Santo K, Thiagalingam A, Rodgers A, et al. Mobile Telephone Text Messaging for Medication Adherence in Chronic Disease: A Meta-analysis. JAMA internal medicine. 2016;176(3):340-9.

41. McGillicuddy JW, Gregoski MJ, Weiland AK, Rock RA, Brunner-Jackson BM, Patel SK, et al. Mobile Health Medication Adherence and Blood Pressure Control in Renal Transplant Recipients: A Proof-ofConcept Randomized Controlled Trial. JMIR Res Protoc. 2013;2(2):e32.

42. Dew MA, Goycoolea JM, Harris RC, Lee A, Zomak R, Dunbar-Jacob J, et al. An internet-based intervention to improve psychosocial outcomes in heart transplant recipients and family caregivers: development and evaluation. J Heart Lung Transplant. 2004;23(6):745-58.

43. DeVito Dabbs A, Song MK, Myers BA, Li R, Hawkins RP, Pilewski JM, et al. A Randomized Controlled Trial of a Mobile Health Intervention to Promote Self-Management After Lung Transplantation. Am J Transplant. 2016;16(7):2172-80.

44. Eurotransplant. Annual report 2016 [Available from:

https://www.eurotransplant.org/cms/mediaobject.php?file=Eurotransplant+JV+PDF.pdf.

45. UZ Leuven. Jaarverslag raad voor transplantatie 2016 [Available from:

https://www.uzleuven.be/sites/default/files/Abdominale_transplantatiechirurgie_en_transplantcoordina tor/jaarverslag/jaarverslag_rvt_2016.pdf. 
Table 1: Demographic, clinical and technological characteristics of sample

\begin{tabular}{|c|c|c|c|c|c|c|c|c|c|c|c|c|c|c|c|c|c|c|c|c|}
\hline \multirow[b]{2}{*}{ Characteristics } & \multicolumn{20}{|c|}{ Participant } \\
\hline & 1 & 2 & 3 & 4 & 5 & 6 & 7 & 8 & 9 & 10 & 11 & 12 & 13 & 14 & 15 & 16 & 17 & 18 & 19 & $\begin{array}{l}\text { Total sample } \\
(n=19)\end{array}$ \\
\hline Age in years ${ }^{1}$ & $\begin{array}{l}30- \\
34\end{array}$ & $\begin{array}{r}50- \\
54\end{array}$ & $\begin{array}{r}60- \\
64\end{array}$ & $\begin{array}{r}55- \\
59\end{array}$ & $\begin{array}{r}40- \\
44\end{array}$ & $\begin{array}{l}65- \\
69\end{array}$ & $\begin{array}{r}60- \\
64\end{array}$ & $\begin{array}{l}25- \\
29\end{array}$ & $\begin{array}{l}65- \\
69\end{array}$ & $\begin{array}{l}60- \\
64\end{array}$ & $\begin{array}{r}60- \\
64\end{array}$ & $\begin{array}{c}40- \\
44\end{array}$ & $\begin{array}{r}45- \\
49\end{array}$ & $\begin{array}{r}50- \\
54\end{array}$ & $\begin{array}{l}60- \\
64\end{array}$ & $\begin{array}{l}65- \\
69\end{array}$ & $\begin{array}{l}20- \\
24\end{array}$ & $\begin{array}{c}65- \\
69\end{array}$ & $\begin{array}{c}50- \\
54\end{array}$ & $\begin{array}{l}\text { Median: } 58 \text { years } \\
\text { Range: } 21-69\end{array}$ \\
\hline $\begin{array}{l}\text { Sex: } \\
\text { Male }\end{array}$ & $\checkmark$ & $\checkmark$ & $\checkmark$ & $\checkmark$ & $\checkmark$ & $\checkmark$ & $\checkmark$ & & $\checkmark$ & $\checkmark$ & $\checkmark$ & & & & & & $\checkmark$ & & & $\mathrm{n}=11 \quad(57.9 \%)$ \\
\hline Female & & & & & & & & $\checkmark$ & & & & $\checkmark$ & $\checkmark$ & $\checkmark$ & $\checkmark$ & $\checkmark$ & & $\checkmark$ & $\checkmark$ & $\mathrm{n}=8 \quad(42.1 \%)$ \\
\hline $\begin{array}{l}\text { Marital status: } \\
\text { Married or cohabiting }\end{array}$ & $\checkmark$ & $\checkmark$ & $\checkmark$ & & & $\checkmark$ & $\checkmark$ & & $\checkmark$ & $\checkmark$ & $\checkmark$ & $\checkmark$ & & $\checkmark$ & & $\checkmark$ & & $\checkmark$ & $\checkmark$ & $\mathrm{n}=13 \quad(68.4 \%)$ \\
\hline Single & & & & $\checkmark$ & $\checkmark$ & & & $\checkmark$ & & & & & $\checkmark$ & & & & $\checkmark$ & & & $\mathrm{n}=5 \quad(26.3 \%)$ \\
\hline Divorced & & & & & & & & & & & & & & & $\checkmark$ & & & & & $n=1 \quad(5.3 \%)$ \\
\hline $\begin{array}{l}\text { Employment: } \\
\text { Disabled }\end{array}$ & $\checkmark$ & & $\checkmark$ & & $\checkmark$ & & & & & & & $\checkmark$ & $\checkmark$ & & $\checkmark$ & & & & $\checkmark$ & $\mathrm{n}=7 \quad(36.8 \%)$ \\
\hline Employed & & $\checkmark$ & & $\checkmark$ & & & $\checkmark$ & $\checkmark$ & & & $\checkmark$ & & & $\checkmark$ & & & & & & $\mathrm{n}=6 \quad(31.6 \%)$ \\
\hline Retired & & & & & & $\checkmark$ & & & $\checkmark$ & $\checkmark$ & & & & & & $\checkmark$ & & $\checkmark$ & & $\mathrm{n}=5 \quad(26.3 \%)$ \\
\hline Student & & & & & & & & & & & & & & & & & $\checkmark$ & & & $\mathrm{n}=1 \quad(5.3 \%)$ \\
\hline $\begin{array}{l}\text { Educational level: } \\
\text { Primary school }\end{array}$ & & & $\checkmark$ & & & & $\checkmark$ & & & & $\checkmark$ & & & & $\checkmark$ & $\checkmark$ & & $\checkmark$ & $\checkmark$ & $\mathrm{n}=7 \quad(36.8 \%)$ \\
\hline Secondary school & $\checkmark$ & $\checkmark$ & & & & & & & $\checkmark$ & & & $\checkmark$ & $\checkmark$ & & & & & & & $\mathrm{n}=5 \quad(26.4 \%)$ \\
\hline Tertiary school & & & & $\checkmark$ & $\checkmark$ & $\checkmark$ & & $\checkmark$ & & $\checkmark$ & & & & $\checkmark$ & & & $\checkmark$ & & & $\mathrm{n}=7 \quad(36.8 \%)$ \\
\hline $\begin{array}{l}\text { Type of transplantation: } \\
\text { Lung }\end{array}$ & & & $\checkmark$ & & $\checkmark$ & & & $\checkmark$ & & & & & & & & $\checkmark$ & & & & $\mathrm{n}=4 \quad(21.1 \%)$ \\
\hline Heart & $\checkmark$ & $\checkmark$ & & $\checkmark$ & & & & & $\checkmark$ & $\checkmark$ & & & & & & & & & & $n=5 \quad(26.3 \%)$ \\
\hline Kidney & & & & & & $\checkmark$ & $\checkmark$ & & & & & $\checkmark$ & $\checkmark$ & & & & $\checkmark$ & & & $n=5 \quad(26.3 \%)$ \\
\hline Liver & & & & & & & & & & & $\checkmark$ & & & $\checkmark$ & $\checkmark$ & & & $\checkmark$ & $\checkmark$ & $\mathrm{n}=5 \quad(26.3 \%)$ \\
\hline $\begin{array}{l}\text { Time since } \\
\text { transplantation in years }\end{array}$ & $\begin{array}{l}5- \\
9 \\
\end{array}$ & $\begin{array}{l}0- \\
4 \\
\end{array}$ & $\begin{array}{c}5- \\
9 \\
\end{array}$ & $\begin{array}{l}0- \\
4\end{array}$ & $\begin{array}{c}10- \\
14\end{array}$ & $\begin{array}{l}0- \\
4\end{array}$ & $\begin{array}{c}20- \\
24\end{array}$ & $\begin{array}{c}10- \\
14\end{array}$ & $\begin{array}{c}20- \\
24\end{array}$ & $\begin{array}{l}5- \\
9\end{array}$ & $\begin{array}{c}10- \\
14\end{array}$ & $\begin{array}{c}10- \\
14\end{array}$ & $\begin{array}{l}5- \\
9\end{array}$ & $\begin{array}{l}5- \\
9\end{array}$ & $\begin{array}{c}0- \\
4\end{array}$ & $\begin{array}{c}10- \\
14\end{array}$ & $\begin{array}{l}0- \\
4\end{array}$ & $\begin{array}{l}5- \\
9\end{array}$ & $\begin{array}{c}15- \\
19\end{array}$ & $\begin{array}{l}\text { Median: } 8 \text { years } \\
\text { Range: } 1 \text { - } 24\end{array}$ \\
\hline $\begin{array}{l}\text { Technology experience }{ }^{2} \text { : } \\
\text { Cell phone }\end{array}$ & & $\checkmark$ & $\checkmark$ & & & $\checkmark$ & & & & $\checkmark$ & $\checkmark$ & $\checkmark$ & $\checkmark$ & & & $\checkmark$ & $\checkmark$ & $\checkmark$ & $\checkmark$ & $n=12(63.1 \%)$ \\
\hline Smartphone & $\checkmark$ & & & $\checkmark$ & $\checkmark$ & & & $\checkmark$ & & & & & & $\checkmark$ & $\checkmark$ & & & & & $\mathrm{n}=6 \quad(31.6 \%)$ \\
\hline Desktop-PC & & & & $\checkmark$ & & $\checkmark$ & & & & $\checkmark$ & $\checkmark$ & & & $\checkmark$ & & $\checkmark$ & & & & $n=9 \quad(47.4 \%)$ \\
\hline Laptop-PC & $\checkmark$ & & $\checkmark$ & $\checkmark$ & $\checkmark$ & & & $\checkmark$ & $\checkmark$ & $\checkmark$ & $\checkmark$ & $\checkmark$ & & $\checkmark$ & $\checkmark$ & $\checkmark$ & $\checkmark$ & & & $\mathrm{n}=15(78.9 \%)$ \\
\hline Tablet-PC & $\checkmark$ & & & & & & & & & & & $\checkmark$ & & & & $\checkmark$ & $\checkmark$ & & & $\mathrm{n}=6 \quad(31.6 \%)$ \\
\hline Internet & $\checkmark$ & $\checkmark$ & $\checkmark$ & $\checkmark$ & $\checkmark$ & $\checkmark$ & & $\checkmark$ & $\checkmark$ & $\checkmark$ & $\checkmark$ & $\checkmark$ & & $\checkmark$ & $\checkmark$ & $\checkmark$ & $\checkmark$ & & & $\mathrm{n}=15(78.9 \%)$ \\
\hline
\end{tabular}

${ }^{1}$ We present years in groups to ascertain the anonymity of the participants; ${ }^{2}$ Information and communication technologies the participant uses in daily life 
Table 2A: Physical activity hindrances as experienced by transplant participants

\begin{tabular}{|l|c|c|}
\hline \multicolumn{1}{|c|}{$\begin{array}{c}\text { Hindrances } \\
\text { 'I find it difficult to be physically active...' }\end{array}$} & $\begin{array}{c}\text { Total sample ( } \mathbf{n}=\mathbf{1 9 )} \\
\text { N participants experiencing } \\
\text { this hindrance } \\
\text { (\% of total sample) }\end{array}$ & $\begin{array}{c}\text { Total number of unique } \\
\text { quotes supporting the } \\
\text { presence of the } \\
\text { hindrance }\end{array}$ \\
\hline When the weather is bad & $12(63.2 \%)$ & 16 \\
\hline Because I have physical discomforts & $11(57.9 \%)$ & 14 \\
\hline Because I am too tired/lack sufficient energy & $8(42.1 \%)$ & 9 \\
\hline Because I am too busy/do not have the time & $7(36.8 \%)$ & 8 \\
\hline Because I am lazy & $5(26.3 \%)$ & 4 \\
\hline Because I do not like (certain) physical activities & $4(21.1 \%)$ & 4 \\
\hline When something breaks my normal routine & $3(15.8 \%)$ & 4 \\
\hline Because I do not like to be physically active alone & $3(15.8 \%)$ & 2 \\
\hline Because I have psychological discomforts & $3(15.8 \%)$ & 2 \\
\hline Because I am embarrassed & $2(10.5 \%)$ & 1 \\
\hline Because it is too expensive & $1(5.3 \%)$ & \\
\hline Because the rehabilitation centre is too far away & $1(5.3 \%)$ & \\
\hline
\end{tabular}




\begin{tabular}{|c|c|c|}
\hline $\begin{array}{l}\text { Hindrances } \\
\text { 'I find it difficult to eat healthy/follow my diet...' }\end{array}$ & $\begin{array}{c}\text { Total sample }(n=19) \\
\text { N participants experiencing } \\
\text { this hindrance } \\
\text { (\% of total sample) }\end{array}$ & $\begin{array}{c}\text { Total number of unique } \\
\text { quotes supporting the } \\
\text { presence of the } \\
\text { hindrance }\end{array}$ \\
\hline When me or my partner are too busy/have little time & $11(57.9 \%)$ & 16 \\
\hline Because sometimes I want something unhealthy/that does not fit my diet & $6(31.6 \%)$ & 12 \\
\hline Because my diet is difficult/not pleasant & $6(31.6 \%)$ & 11 \\
\hline When I have easy access to unhealthy food & $6(31.6 \%)$ & 10 \\
\hline Because I do not understand why it is important/nothing changes to my body & $6(31.6 \%)$ & 6 \\
\hline Because I have/it leads to physical discomforts & $5(26.3 \%)$ & 5 \\
\hline When I have visitors & $4(21.1 \%)$ & 7 \\
\hline Because I lack inspiration/do not know how to eat healthy & $4(21.1 \%)$ & 4 \\
\hline Because I am always feeling hungry & $4(21.1 \%)$ & 4 \\
\hline When something interrupts my normal routine (e.g. holidays) & $3(15.8 \%)$ & 3 \\
\hline When healthy food is not available & $3(15.8 \%)$ & 3 \\
\hline Because I am rarely feeling hungry & $3(15.8 \%)$ & 3 \\
\hline When others have to take care of my food & $3(15.8 \%)$ & 3 \\
\hline Because my partner has a different diet & $2(10.5 \%)$ & 2 \\
\hline Because I find it difficult to refuse & $1(5.3 \%)$ & 1 \\
\hline Because I am convinced I can eat anything & $1(5.3 \%)$ & 1 \\
\hline When I have psychological discomforts & $1(5.3 \%)$ & 1 \\
\hline When I have too much time to shop & $1(5.3 \%)$ & 1 \\
\hline Because my partner likes to go to restaurants & $1(5.3 \%)$ & 1 \\
\hline
\end{tabular}


Table 2C: Medication adherence hindrances as experienced by transplant participants

\begin{tabular}{|l|c|c|}
\multicolumn{1}{|c|}{$\begin{array}{c}\text { Hindrances } \\
\text { 'I find it difficult to adhere to my immunosuppressive } \\
\text { medication...' }\end{array}$} & $\begin{array}{c}\text { Total sample (n= 19) } \\
\text { N participants experiencing } \\
\text { this hindrance } \\
\text { (\% of total sample) }\end{array}$ & $\begin{array}{c}\text { Total number of unique } \\
\text { quotes supporting the } \\
\text { presence of the } \\
\text { hindrance }\end{array}$ \\
\hline When something breaks my normal routine & $14(73.7 \%)$ & 18 \\
\hline When I am too busy doing other things & $11(57.9 \%)$ & 15 \\
\hline Because I am not sure about the instructions/lack sufficient knowledge & $11(57.9 \%)$ & 14 \\
\hline Because I experience side-effects & $9(47.4 \%)$ & 15 \\
\hline Because I do not understand the strictness of my regime & $6(31.6 \%)$ & 12 \\
\hline Because I experience problems with adherence facilitators & $6(31.6 \%)$ & 9 \\
\hline Because I am forgetful & $5(26.3 \%)$ & 5 \\
\hline When nobody reminds me to take them & $4(21.1 \%)$ & 4 \\
\hline Because I have to take so many medications & $4(21.1 \%)$ & 4 \\
\hline Because I forget to take/prepare my medication when going out & $4(21.1 \%)$ & 4 \\
\hline When I fall asleep/oversleep & $3(15.8 \%)$ & \\
\hline When something in my medication regimen changes & $1(5.3 \%)$ & \\
\hline Because some pills are too small & $1(5.3 \%)$ & \\
\hline When others notice me taking them & $1(5.3 \%)$ & \\
\hline Because I find it difficult to remove them out of the blister & $1(5.3 \%)$ & 1 \\
\hline Because I have a bad vision & $1(5.3 \%)$ & 1 \\
\hline
\end{tabular}


Figure 1A, B: Typical 'contextual inquiry interview' scenes
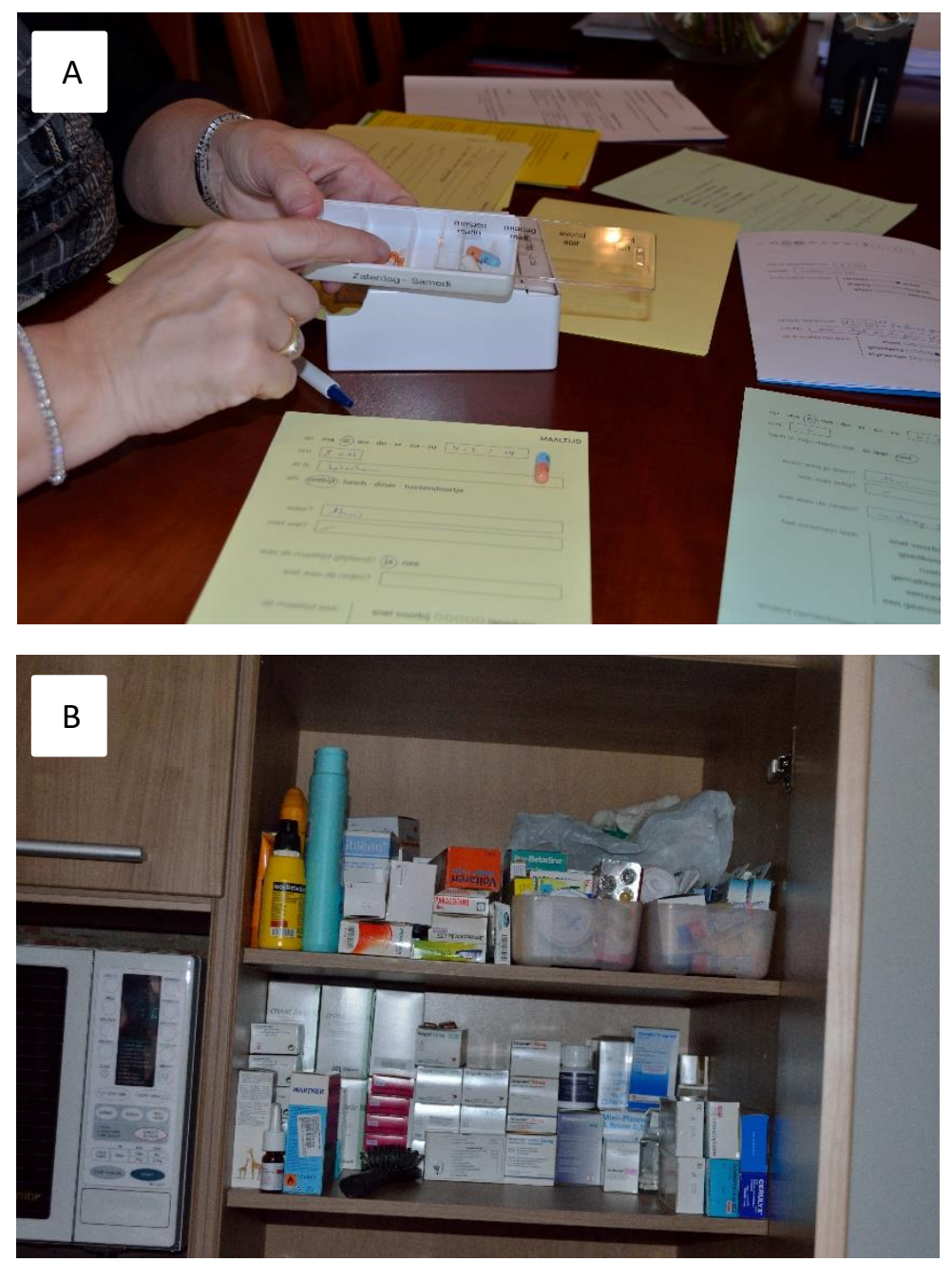

Typical 'contextual inquiry interview' scenes conducted during a second home visit; A) The diary that participant 14 kept is scattered over the kitchen table, she is explaining how, when, where and why she uses the medication pillbox; the audio recorder is standing in the background; B) Participant 5 shows us where he kept his large medication stock, in the kitchen cabinet 


\section{Figure 2A, B: Participant 6}
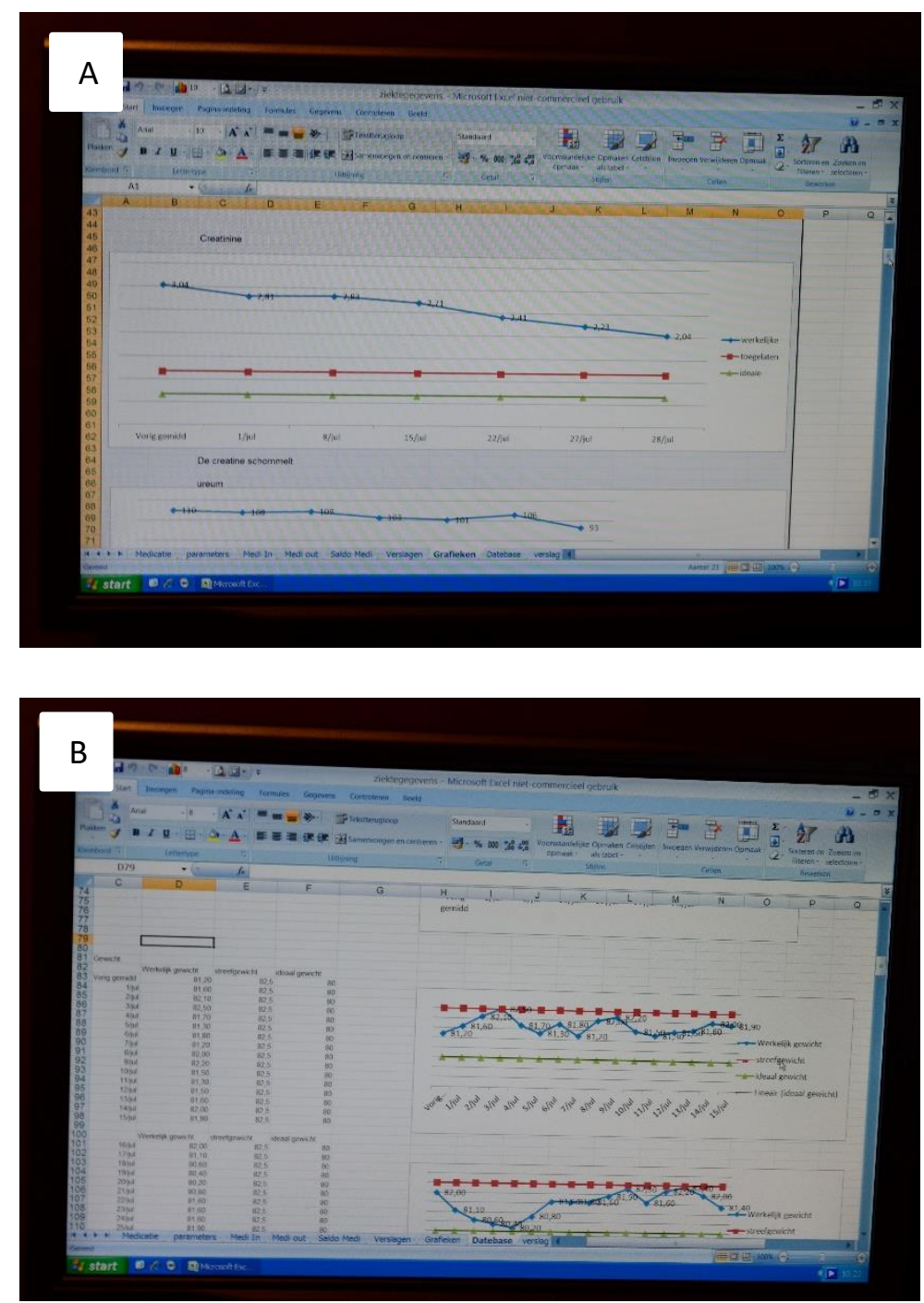

A) Creatinine graph; upper curve is the participant's personal level, middle curve is the permitted level and the lower curve is the ideal level; B) Weight input (left) and graphs; upper curve is the target weight, middle curve is the current weight and lower curve is the ideal weight 


\section{Figure 3: Participant 5}

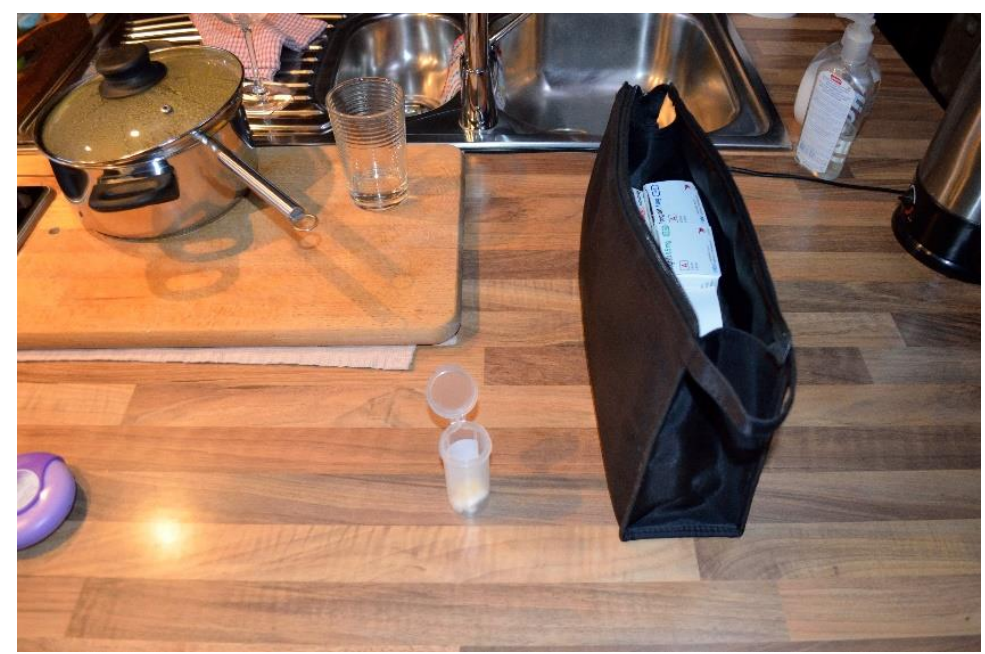

On the right: participant's "purse" to take medication with him when going out; on the left: small cup to take medication for a very short period (e.g. hospital visit) 


\section{Figure 4A, B: Participant 3}
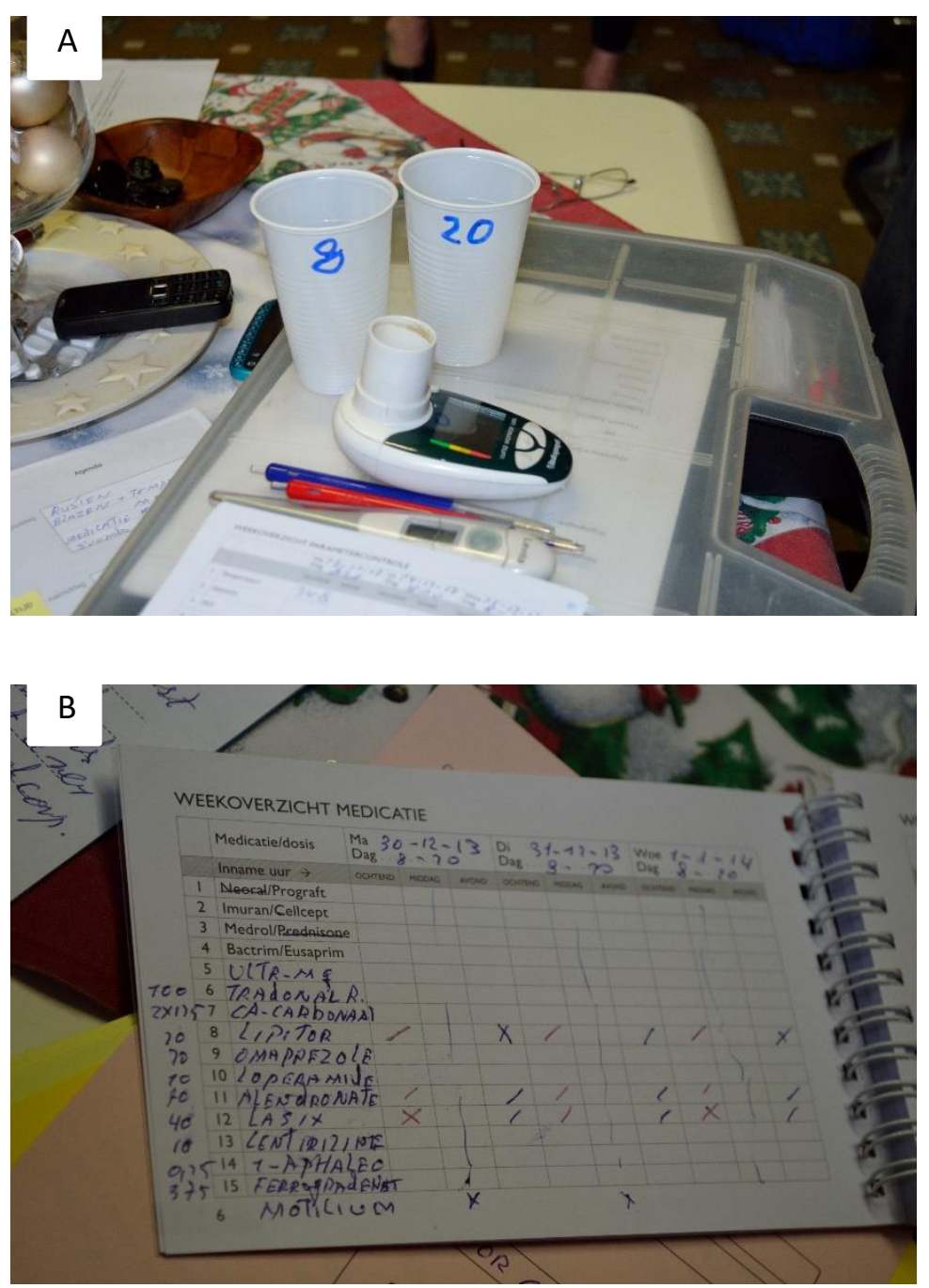

A) Participant shows how he puts his medication cups, containing the medication for 8 PM ('20') that evening and 8 AM (' 8 ') for the next morning, on top of his large medication box, together with his thermometer, spirometer and diary (below). Of note, although spirometry use was not a focus of this study, do notice how dirty it is on the inside; B) Participant shows us his diary, containing medication lists where he marks his medication: red for the morning medication, blue for the evening. Notice the dates on top of the diary (30 December to 1 January), and that the date of our home visit was 23 December. As the participant explained, he already completed some of his diary until February 


\section{Figure 5: Participant 9}

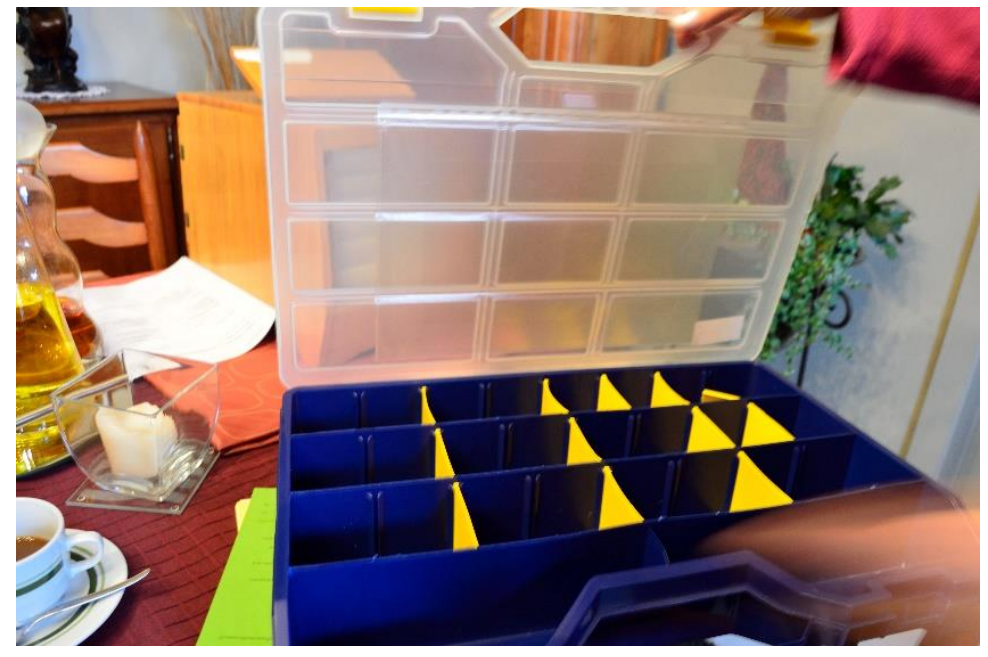

Participant shows us the medication box from the hospital; He never uses it in his daily life, but does fill it and takes it with him when going to the hospital. 


\section{ONLINE SUPPLEMENTS}

\section{Details on physical activity hindrances as experienced by transplant participants}

\begin{tabular}{|c|c|c|c|c|c|c|c|c|c|c|c|c|c|c|c|c|c|c|c|c|}
\hline & Par & cip & & & & & & & & & & & & & & & & & & \\
\hline $\begin{array}{l}\text { Hindrances } \\
\text { 'I find it difficult to be physically } \\
\text { active...' }\end{array}$ & 1 & 2 & 3 & 4 & 5 & 6 & 7 & 8 & 9 & 10 & 11 & 12 & 13 & 14 & 15 & 16 & 17 & 18 & 19 & $\begin{array}{l}\text { Total sample }(n=19) \\
\mathrm{N} \text { participants experiencing } \\
\text { this hindrance (total number of } \\
\text { unique quotes supporting the } \\
\text { presence of the hindrance) }\end{array}$ \\
\hline Because I am lazy & 1 & & & & & & & & 1 & & 1 & & 1 & & & 1 & & & & $5(5)$ \\
\hline When something breaks my normal routine & 2 & 1 & & 1 & & & & & & & & & & & & & & & & $3(4)$ \\
\hline Because I have physical discomforts & & 1 & & 2 & 1 & 1 & 1 & & 1 & & 2 & & 2 & & 1 & 1 & & 1 & & $11(14)$ \\
\hline When the weather is bad & & 1 & 1 & & 1 & 2 & 1 & & 2 & 1 & 2 & 1 & & 1 & 2 & 1 & & & & $12(16)$ \\
\hline Because I am too busy/do not have the time & & 1 & 1 & 1 & & & & 1 & & & 1 & & & 2 & & & 1 & & & $7(8)$ \\
\hline $\begin{array}{l}\text { Because I am too tired/lack sufficient } \\
\text { energy }\end{array}$ & & & & 1 & 1 & & & & 2 & & & & 1 & 1 & & 1 & 1 & & 1 & $8(9)$ \\
\hline Because I have psychological discomforts & & & & 1 & & & & & & & & & & & 1 & & & & 1 & $3(3)$ \\
\hline $\begin{array}{l}\text { Because I do not like (certain) physical } \\
\text { activities }\end{array}$ & & & & & 1 & & & & 1 & 1 & & & 1 & & & & & & & $4(4)$ \\
\hline $\begin{array}{l}\text { Because I do not like to be physically active } \\
\text { alone }\end{array}$ & & & & & 1 & & & & & & & & & 2 & 1 & & & & & $3(4)$ \\
\hline Because I am embarrassed & & & & & 1 & & & & & & & & 1 & & & & & & & $2(2)$ \\
\hline Because it is too expensive & & & & & 2 & & & & & & & & & & & & & & & $1(2)$ \\
\hline $\begin{array}{l}\text { Because the rehabilitation centre is too far } \\
\text { away }\end{array}$ & & & & & 1 & & & & & & & & & & & & & & & $1(1)$ \\
\hline
\end{tabular}




\section{Details on eating habits hindrances as experienced by transplant participants}

\section{Participant}

Hindrances

'I find it difficult to eat healthy/follow my diet...'
1

(2)
34

4

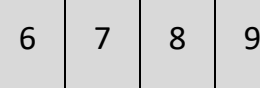

Because sometimes I want something

unhealthy/that does not fit my diet

When me or my partner are too busy/have

little time

When I have easy access to unhealthy food

Because my diet is difficult/not pleasant

When something interrupts my normal

routine (e.g. holidays)

Because I have/it leads to physical

discomforts

Because my partner has a different diet

When healthy food is not available

Because I lack inspiration/do not know

how to eat healthy

When I have visitors

Because I am always feeling hungry

When I have psychological discomforts

Because I am rarely feeling hungry

Because I do not understand why it is

important/nothing changes to my body

Because I find it difficult to refuse

Because I am convinced I can eat anything

When others have to take care of my food

When I have too much time to shop

Because my partner likes to go to

restaurants
$9 \quad 10$

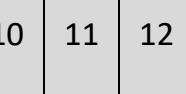

1314

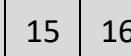

1516

Total sample $(n=19)$

$\mathrm{N}$ participants experiencing this hindrance (total number of unique quotes supporting the presence of the hindrance)

2

6 (12)

$11(16)$

$6(10)$

$6(11)$

3 (3)

$5(5)$

$2(2)$

$3(3)$

4 (4)

1

1

\begin{tabular}{|c|l|l|l|l|l|l|l|l|l|l|l|l|}
1 & & & & & & & 4 & & & & & 1 \\
\hline
\end{tabular}

$4(7)$

$4(7)$

4 (4)

$1(1)$

3 (3)

\begin{tabular}{l|l|l|l|l|l|l|l|l|l|}
1 & & & & & & \\
\hline
\end{tabular}

1

$6(6)$

$1(1)$

$1(1)$

$3(3)$

1 (1)

1 (1) 


\section{Details on medication adherence hindrances as experienced by transplant participants}

\begin{tabular}{|c|c|c|c|c|c|c|c|c|c|c|c|c|c|c|c|c|c|c|c|c|}
\hline \multirow[b]{2}{*}{$\begin{array}{l}\text { Hindrances } \\
\text { 'I find it difficult to adhere to my } \\
\text { immunosuppressive medication...' }\end{array}$} & \multicolumn{20}{|c|}{ Participant } \\
\hline & 1 & 2 & 3 & 4 & 5 & 6 & 7 & 8 & 9 & 10 & 11 & 12 & 13 & 14 & 15 & 16 & 17 & 18 & 19 & $\begin{array}{l}\text { Total sample }(n=19) \\
\text { N participants experiencing this } \\
\text { hindrance (total number of } \\
\text { unique quotes supporting the } \\
\text { presence of the hindrance) }\end{array}$ \\
\hline When something breaks my normal routine & 2 & 2 & 1 & 1 & 1 & 1 & 1 & & & 2 & 1 & 1 & 1 & 2 & 1 & 1 & & & & $14(18)$ \\
\hline When I am too busy doing other things & 1 & 1 & 1 & 1 & 1 & 1 & & 1 & 1 & 1 & & & & 4 & & & & & 2 & $11(15)$ \\
\hline $\begin{array}{l}\text { Because I am not sure about the } \\
\text { instructions/lack sufficient knowledge }\end{array}$ & 1 & & 1 & & & 1 & & & 2 & & 1 & 2 & & 1 & 1 & 1 & & 1 & 2 & $11(14)$ \\
\hline When nobody reminds me to take them & 1 & & & & & & & & 1 & & 1 & & & 1 & & & & & & $4(4)$ \\
\hline $\begin{array}{l}\text { Because I experience problems with } \\
\text { adherence facilitators }\end{array}$ & & & 3 & & & & & & 2 & 1 & & & & 1 & 1 & & & & 1 & $6(9)$ \\
\hline Because some pills are too small & & & 1 & & & & & & & & & & & & & & & & & $1(1)$ \\
\hline Because I experience side-effects & & & & & 1 & 1 & 1 & & 3 & 1 & & 2 & & & 1 & & & 2 & 3 & $9(15)$ \\
\hline Because I am forgetful & & & & & 1 & & 1 & & 1 & & & & & & 1 & & & & 1 & $5(5)$ \\
\hline Because I have to take so many medications & & & & & 1 & & & & 1 & & & & & & 1 & & & 1 & & $4(4)$ \\
\hline $\begin{array}{l}\text { Because I forget to take/prepare my } \\
\text { medication when going out }\end{array}$ & & & & & 1 & & & & & & & & & 1 & 1 & & & & 1 & $4(4)$ \\
\hline When I fall asleep/oversleep & & & & & & 1 & 1 & & & & & & & 2 & & & & & & $3(4)$ \\
\hline $\begin{array}{l}\text { Because I do not understand the strictness } \\
\text { of my regime }\end{array}$ & & & & & & 1 & & & 4 & & 1 & & & 3 & 2 & & & 1 & & $6(12)$ \\
\hline When others notice me taking them & & & & & & & & 1 & & & & & & & & & & & & $1(1)$ \\
\hline $\begin{array}{l}\text { Because I find it difficult to remove them out } \\
\text { of the blister }\end{array}$ & & & & & & & & & 1 & & & & & & & & & & & $1(1)$ \\
\hline $\begin{array}{l}\text { When something in my medication regimen } \\
\text { changes }\end{array}$ & & & & & & & & & 2 & & & & & & & & & & & $1(2)$ \\
\hline Because I have a bad vision & & & & & & & & & & & & & & & 1 & & & & & $1(1)$ \\
\hline
\end{tabular}


Translated booklet to assess transplant patients' general daily activities and organization, one week preceding the contextual inquiry interview

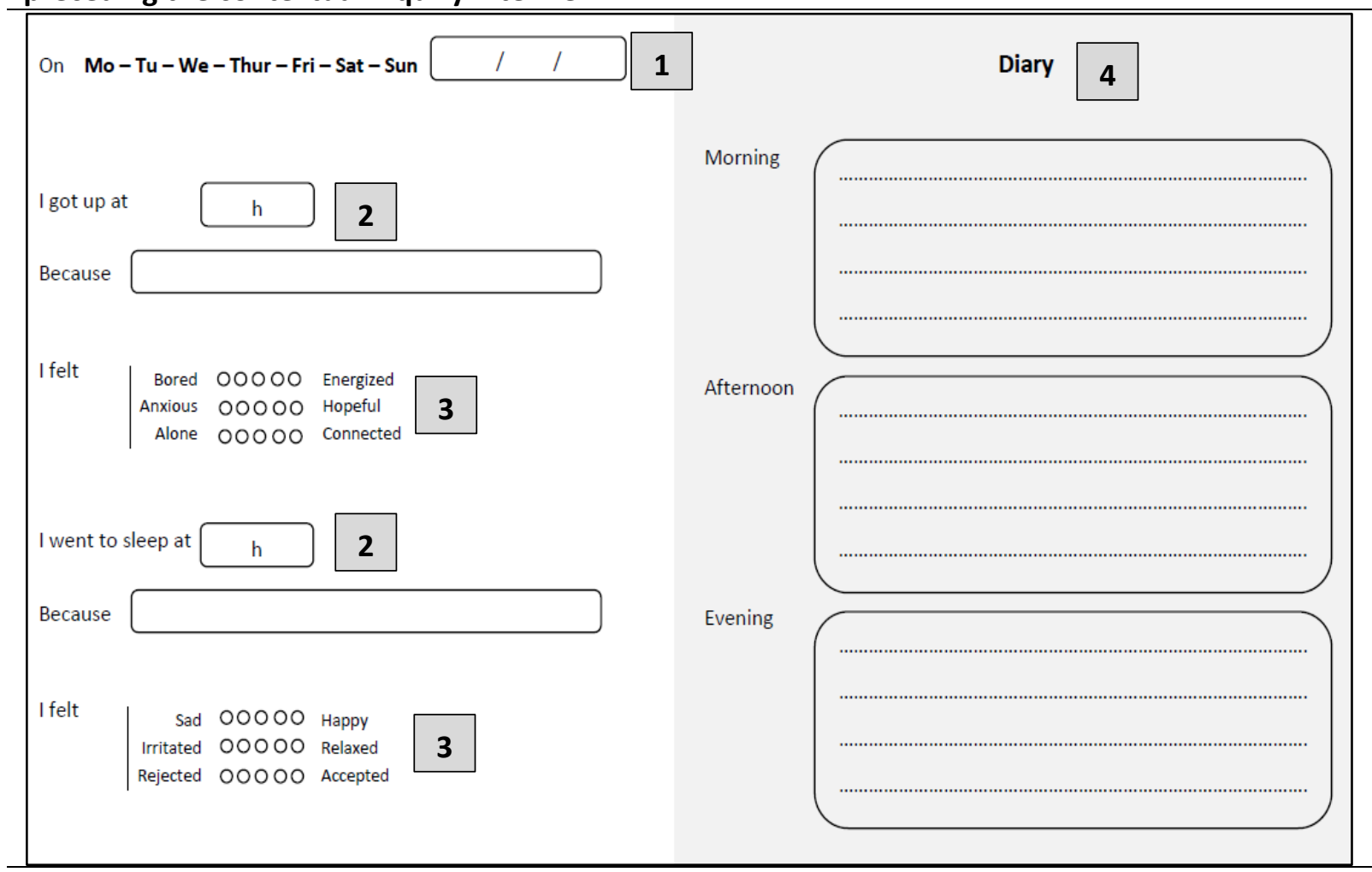

1. The respective day and date of the week; 2 . Right after/before the patient got out of bed/went to sleep, he was asked to write down the hour and the reason (e.g.'I overslept', 'my alarm went off' or 'I was tired'); 3. Total of six Likert-scales, three to complete when the patient got up, three for when going to sleep, ranging between opposite motivational subcomponents, based on the behavioural model for persuasive design (i.e. pleasure/pain, hope/fear, acceptance/rejection); 4. All relevant activities the patient did during the day, not limited to medication, eating or physical activity, in key words. 
Translated example of sheet to assess transplant patient's daily physical activity, one week preceding the contextual inquiry interview

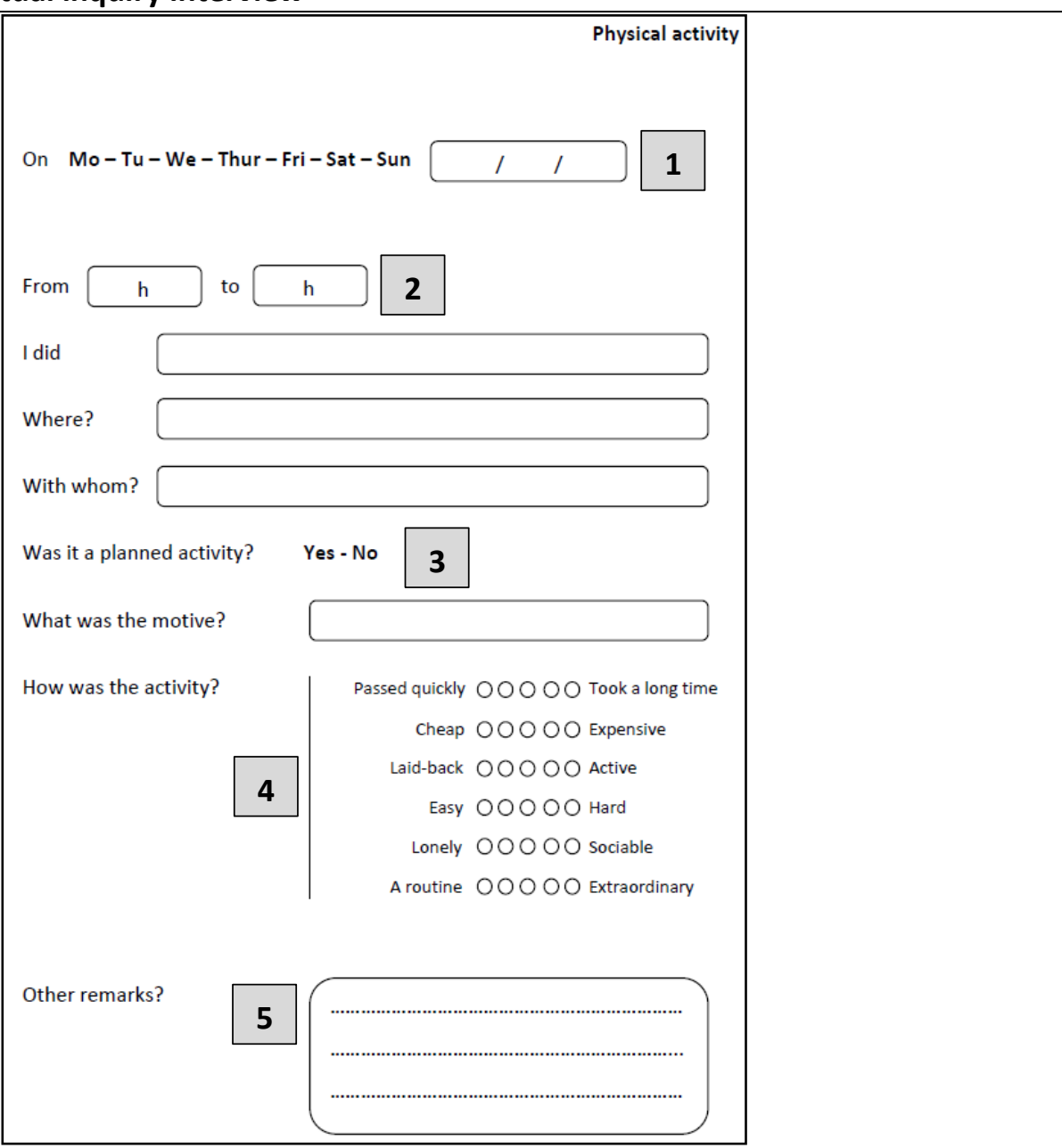

1. The respective day and date of the week; 2 . Details on the physical activity: timespan, what it was, where it took place and with whom; 3. Whether or not it was a planned activity and the motive (e.g. I always walk to the market on Tuesday); 4. Total of six Likert-scales, ranging between opposite subcomponents of abilities, based on the behavioural model for persuasive design (i.e. time, money, physical effort, brain cycles, social deviance and non-routine); 5. Opportunity for patients to write down additional remarks 